\title{
Improved Rigid-Plastic Method for Predicting the Ultimate Strength of Concrete Walls Restrained on Three Sides
}

\author{
J.H. Doh ${ }^{1[0000-0002-4354-3262]}$, N.M. Ho ${ }^{2[0000-0002-7119-1276]}$ and T. Peters ${ }^{3}$ \\ ${ }^{1}$ School of Engineering and Built Environment, Griffith University, QLD 4222, Australia \\ ${ }^{2}$ EDGE Consulting Engineers, EDGE Tweed Heads, NSW 2486, Australia \\ ${ }^{3}$ EDGE Consulting Engineers, EDGE Gold Coast, QLD 4212, Australia \\ j.dohegriffith.edu.au
}

\begin{abstract}
The modern-day popularity of tilt-up construction, shear walls and concrete cores in multi-storey buildings means that the construction of concrete walls with various boundary conditions and higher slenderness ratios, along with the presence of openings, has become common. The design of such elements under eccentric axial loads, however, could be outside the restrictions of current major design codes such as the Eurocode 2 (EC2-2004), the American Concrete Institute Code (ACI318-2014) and the Australian Concrete Standard (AS36002018). There have been many experimental and numerical studies on the behaviour of both one-way action walls and two-way action walls supported on four sides, with and without openings in the range of high slenderness ratios (up to 50). Efforts have also been made to develop design models capable of predicting the axial load capacity of such walls. However, research into the behaviour of two-way action walls supported on three sides (TW3S walls) is still relatively unexplored and further studies in this area are needed. Recent research has demonstrated that a rigid-plastic approach could be used to describe the behaviour of TW3S walls with and without openings. Although predictions obtained using the rigid-plastic approach showed reasonably good agreement with experimental test data, the scope of the analysis approach is considered limited. In this study, a validated finite element method, using the ABAQUS program, was employed to improve the rigid-plastic model, covering a broader spectrum of designs for axially-loaded TW3S walls. The reliability of the modified model was confirmed through comparisons with the available test data.
\end{abstract}

Keywords: Concrete Walls, Axial Load, Rigid-Plastic Method.

\section{Introduction}

Cast-in-situ or precast reinforced concrete (RC) walls are commonly used in multi-storey buildings to withstand gravitational and lateral loadings. Walls restrained along the top and bottom edges by floors, with free vertical edges, subjected to in-plane axial loads behave in one-way action (OW). Axially-loaded walls can also behave in twoway action with lateral support on three sides (TW3S) or four sides (TW4S), formed 
by floors and intersecting walls, when they are combined to form an isolated box, a bundled box, a coupled core, or a geometric, U-, T- or L-shape [1]. In many circumstances, walls are pierced with openings due to architectural requirements or functional modifications of the structures. However, these openings are a source of weakness and can size-dependently reduce the stiffness and load-bearing capacity of the structure [2].

The crack patterns developed at failure of the two-way action walls (TW walls) axially loaded with an eccentricity at the 'kern' of a section, $t_{w} / 6$, were similar to the yield lines of members under transverse loading, as observed in previous research results [310]. This similarity suggested that a rigid-plastic approach could be used to describe the biaxial effects on such TW walls. Popescu et al. [11] and Ho and Doh [9] proposed analytical models, based on the rigid-plastic approach, to evaluate the failure loads of axially-loaded TW4S and TW3S walls, respectively. Although these researchers illustrated that predictions using the rigid-plastic approach showed reasonably good agreement with their experimental test data, the scope of the analysis approach is considered limited. In this study, a validated finite element method (FEM), using the ABAQUS program, was employed to improve the rigid-plastic model, covering a broader spectrum of designs for axially-loaded TW3S walls. The reliability of the modified model was confirmed through comparisons with the available test data.

\section{Improved rigid-plastic method}

The rigid-plastic approach for TW3S walls was initially developed by Ho and Doh [9]. Details of the full derivation can be found in their publication [9]. In this paper, the improved rigid-plastic method proposed by Ho [12] will be briefly presented.

The external and internal work can be obtained using a general work equation developed by Popescu et al. [11]:

$$
-\int\left(n_{u x, u y} \delta d x, y\right)_{\text {each boundary }}=\sum\left(\int m_{c} \theta d s\right)_{\text {each yield line }}
$$

where $n_{u x}, n_{u y}$ are the uniform in-plane compressive force per unit length applied in the $x$ (horizontal) and $y$ (vertical) directions, respectively; $\delta$ is the virtual displacement; $\theta$ is the rotation of the region about its axis of rotation; and $m_{c}$ is the membrane moment. The equation that defines the membrane moment is:

$$
m_{c}=\frac{1}{4} v_{1} f_{c}^{\prime}\left(t_{w}-\delta_{p}\right)^{2}
$$

where $f^{\prime}{ }_{c}$ is the compressive strength of concrete; $t_{w}$ is the wall thickness; $\delta_{p}$ is the maximum displacement at peak load. $v_{l}$ is the effectiveness factor and is defined as $v_{1}=$ $\eta_{f c} \eta_{\varepsilon} ; \eta_{f c}$ is the strength reduction factor reflecting the brittleness of concrete, and is given by $\eta_{f c}=\left(f_{c 0} / f_{c}^{\prime}\right)^{1 / 3} \leq 1$ with $f_{c 0}=30 \mathrm{MPa} ; \eta_{\varepsilon}$ is the strength reduction factor reflecting the influence of transverse cracking, and is taken as 0.55 .

The yield-line patterns and the maximum displacement at peak load are determined as follows: 


\subsection{Yield-line patterns}

It is assumed that the patterns of yield lines include both real and fictitious yield lines. These proposed patterns were justified by the crack patterns observed in the experimental tests $[4,6,7,9,10]$ and by those obtained from the parametric studies using the FEM [12]. The FEM, using the ABAQUS program, was developed and validated in the previous study by Ho and Doh [9] for predicting the behaviour of $\mathrm{RC}$ walls with various support conditions under eccentric axial loading. Details of the crack patterns of the FEM results can be found in the PhD Thesis [12]. Figs. 1 and 2 show the proposed simplified yield-line patterns for solid TW3S walls and TW3S walls with openings, respectively. The procedure to determine the yield-line patterns for TW3S walls with and without openings is provided by Ho [12]. Additionally, the geometric compatibility suggested by Baker et al. [13] is adopted for the proposed patterns.

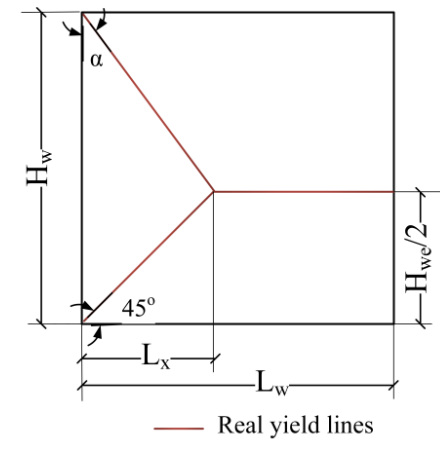

(a) Walls with $H_{w} / L_{w} \leq 1.4$

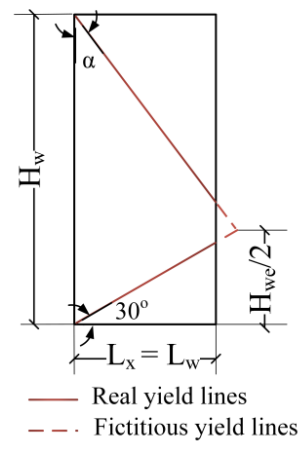

(b) Walls with $H_{w} / L_{w}>1.4$

Fig. 1. Proposed yield-line patterns for TW3S solid walls.

\subsection{Maximum out-of-plane deflection at peak load}

The maximum deflection at peak load, $\delta_{p}$, is calculated as:

$$
\delta_{\mathrm{p}}=\lambda \mathrm{e}_{\mathrm{a}}
$$

in which $e_{a}$ is the lateral deflection for TW3S walls defined in AS3600 [14]; $\lambda$ is the fine-tuning parameter, and is defined as:

$$
\begin{gathered}
\lambda=\frac{\mathrm{A}}{\left(H_{w} / \mathrm{t}_{w}\right)^{\mathrm{B}}} \times\left[1+\left(\frac{e}{t_{w}}-\frac{t_{w}}{6}\right) \times \frac{H_{w}}{L_{w}} \times \mathrm{C}\right] \text { for solid walls } \\
\lambda=\frac{\mathrm{A}}{\left(H_{w} / \mathrm{t}_{w}\right)^{\mathrm{B}}} \times\left[1+\left(\frac{e}{t_{w}}-\frac{t_{w}}{6}\right) \times \frac{H_{w}}{L_{w}} \times \mathrm{C}\right] \times \frac{\mathrm{D}}{\left(\eta_{o x} / \eta_{o y}\right)^{\mathrm{E}}} \text { for walls with openings }
\end{gathered}
$$

where $H_{w}$ is the floor-to-floor height of the wall; $L_{w}$ is the wall length; $\eta_{o x}$ and $\eta_{o y}$ are the distance of opening centre to the edge in the horizontal and vertical directions, 
respectively. A, B, C, D and E factors were calibrated from the FEM results using regression analysis for walls with $t_{w} / 6 \leq e \leq t_{w} / 3$; and $\mathrm{A}=43.6, \mathrm{~B}=1.04, \mathrm{C}=4.5, \mathrm{D}=$ 0.93 and $\mathrm{E}=0.65$. Further information concerning the lower limit imposed at $e=t_{w} / 6$ is given by Ho [12].

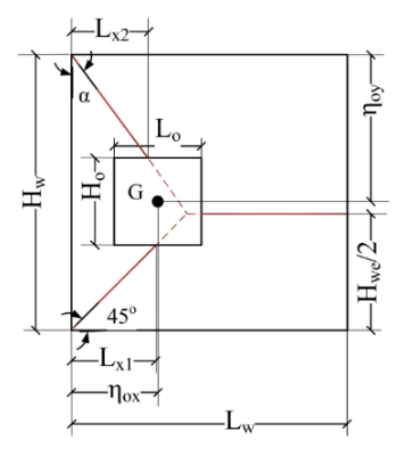

(a) Pattern 1

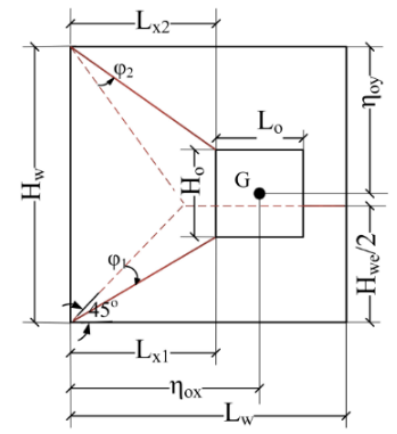

(c) Pattern 3

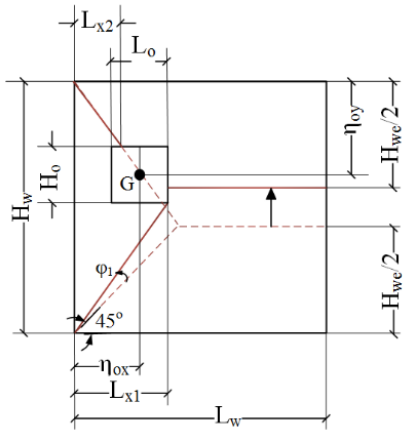

(e) Pattern 5

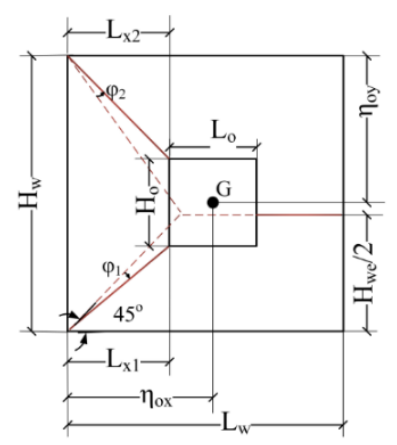

(b) Pattern 2

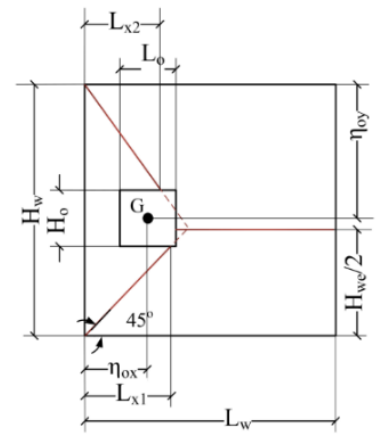

(d) Pattern 4

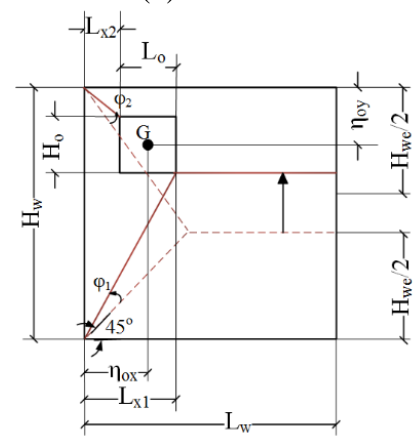

(f) Pattern 6

_ Real yield lines of a wall with an opening

- - Fictitious yield lines of an idential solid wall counterpart

Fig. 2. Proposed yield-line patterns for TW3S solid walls. 


\section{Comparative study}

Table 1 compares the failure loads predicted by the proposed rigid-plastic model with the available test results $[4,7,9,10]$. The ratio of the predicted strength to actual strength varied from 0.6 to 1.34 , with an overall mean of 0.95 and a standard deviation of 0.15 . For the solid walls, the average ratio of the predicted strength to actual strength was 1.00 , with a standard deviation of 0.09 . Concerning the walls with openings, the model provided a good conservative mean of 0.91 , but a relatively high standard deviation of 0.18 . Notably, the model safely and reasonably predicted the failure loads for wall panels, except the WD2 panel, which had a great discrepancy in the predicted value. It should also be noted that the predicted value from the proposed rigid-plastic model for the WD2 panel was $440.8 \mathrm{kN}$, comparatively close to the predicted FEM value of $406.1 \mathrm{kN}$ [12]. If the WD2 value was removed, the mean and the standard deviation would be 0.87 and 0.14 , respectively.

Table 1. Comparison of test results and predicted failure loads.

\begin{tabular}{|c|c|c|c|c|c|c|}
\hline Ref. & $\begin{array}{l}\text { Panel des- } \\
\text { ignation }\end{array}$ & $\begin{array}{c}N_{u w, T e s t} \\
(\mathrm{kN})\end{array}$ & $\begin{array}{l}\text { Eq. (1) solid } \\
(\mathrm{kN})\end{array}$ & $\begin{array}{c}\text { Eq. (1) opening } \\
(\mathrm{kN})\end{array}$ & $\frac{\text { Eq. }(1)_{\text {solid }}}{N_{u w, T e s t}}$ & $\frac{\text { Eq. (1) opening }}{N_{u w, \text { Test }}}$ \\
\hline \multirow{6}{*}{ [4] } & TSNO & 502.2 & 514.6 & \multirow{2}{*}{$\mathrm{N} / \mathrm{A}^{\#}$} & 1.02 & \multirow{2}{*}{$\mathrm{N} / \mathrm{A}^{\#}$} \\
\hline & TSHO & 809.3 & 705.3 & & 0.87 & \\
\hline & TSNC & 353.2 & \multirow{4}{*}{$\mathrm{N} / \mathrm{A}^{\#}$} & 404.8 & \multirow{4}{*}{$\mathrm{N} / \mathrm{A}^{\#}$} & 1.15 \\
\hline & TSNR & 421.1 & & 424.6 & & 1.01 \\
\hline & TSHC & 715.2 & & 554.9 & & 0.78 \\
\hline & TSHL & 668.1 & & 402.1 & & 0.60 \\
\hline [7] & TW3S-NF & 450.0 & N/A & 380.4 & N/A ${ }^{\#}$ & 0.85 \\
\hline \multirow{19}{*}[9,10]{} & WS1 & 620.0 & 603.4 & & 0.97 & \\
\hline & WS1a & 499.1 & 496.2 & & 0.99 & \\
\hline & WS1b & 450.6 & 482.9 & & 1.07 & \\
\hline & WS1c & 398.4 & 377.7 & & 0.95 & \\
\hline & WS2 & 500.1 & 569.4 & $\mathrm{~N} / \mathrm{A}^{\#}$ & 1.14 & $\mathrm{~N} / \mathrm{A}^{\#}$ \\
\hline & WS2a & 410.3 & 402.3 & & 0.98 & \\
\hline & WS2b & 355.9 & 401.7 & & 1.13 & \\
\hline & WS3a & 471.7 & 413.8 & & 0.88 & \\
\hline & WS4 & 475.7 & 476.3 & & 1.00 & \\
\hline & WL1 & 529.5 & \multirow{8}{*}{$\mathrm{N} / \mathrm{A}^{\#}$} & 409.5 & \multirow{8}{*}{ N/A } & 0.77 \\
\hline & WC1 & 512.5 & & 455.8 & & 0.89 \\
\hline & WR1 & 480.5 & & 477.7 & & 0.99 \\
\hline & WL2 & 358.5 & & 311.6 & & 0.87 \\
\hline & WC2a & 449.0 & & 395.2 & & 0.88 \\
\hline & WC $2 b$ & 414.9 & & 371.5 & & 0.90 \\
\hline & WR2 & 486.7 & & 389.7 & & 0.80 \\
\hline & WD2 & 329.8 & & 440.8 & & 1.34 \\
\hline & \multicolumn{3}{|c|}{ Mean } & & 1.00 & 0.91 \\
\hline & \multicolumn{3}{|c|}{ Standard deviation } & & 0.09 & 0.18 \\
\hline
\end{tabular}

\# Not applicable 


\section{Conclusions}

In this paper, the rigid-plastic model for evaluating the ultimate load of TW3S walls was improved, which covers a vast range of conditions encountered in practice. The modified model was established based on several assumptions from the experimental and numerical observations, and was calibrated with the FEM results. This model has shown good predictions and correlations with the experimental results. In future, when further research is undertaken, the proposed model could be further validated and enhanced, improving its reliability and practicality.

\section{References}

1. Menegon, S.J., Wilson, J.L., Lam, N.T.K., Gad, E.F.: RC Walls in Australia: Reconnaissance Survey of Industry and Literature Review of Experimental Testing. Australian Journal of Structural Engineering 18(1), 24-40 (2017).

2. Seddon, A.E.: The Strength of Concrete Walls under Axial and Eccentric Loads. In: Symposium on the Strength of Concrete Structures, London, UK (1956).

3. Doh, J.H., Fragomeni, S.: Evaluation of Experimental Work on Concrete Walls in One and Two-way Action. Australian Journal of Structural Engineering 6(1), 37-52 (2005).

4. Doh, J.H., Lee, D.J., Guan, H., Loo, Y.C.: Concrete Wall with Various Support Conditions. In: 4th International Conference on Advances in Structural Engineering and Mechanics (ASEM'08), Korea (2008).

5. Lee, D.J.: Experimental and Theoretical Studies of Normal and High Strength Concrete Wall Panels with Openings. PhD Thesis, Griffith University, Australia (2008).

6. Doh, J.H., Loo, Y.C., Fragomeni, S.: Concrete Walls with and without Openings Supported on Three Sides. In: Incorporating Sustainable Practice in Mechanics and Structures of Materials, 209-214 (2010).

7. Lima, M.M., Doh, J.H., Miller, D.: Experimental Study of RC Walls with Openings Strengthened by CFRP. In: 23rd Australasian Conference on the Mechanics of Structures and Materials (ACMSM23), Byron Bay, Australia (2014).

8. Popescu, C., Sas, G., Sabău, C., Blanksvärd, T.: Effect of Cut-out Openings on the Axial Strength of Concrete Walls. Journal of Structural Engineering 142(11), (2016).

9. Ho, N.M., Doh, J.H.: Experimental and Numerical Investigations of Axially Loaded RC Walls Restrained on Three Sides. The Structural Design of Tall and Special Buildings 27(7), 1-23 (2018). doi: 10.1002/tal.1459

10. Ho, N.M., Doh, J.H.: Prediction of Ultimate Strength of Concrete Walls Restrained on Three Sides. Structural Concrete, (2019). doi: 10.1002/suco.201800188

11. Popescu, C., Schmidt, J.W., Goltermann, P., Sas, G.: Assessment of RC Walls with Cut-out Openings Strengthened by FRP Composites Using a Rigid-plastic Approach. Engineering Structures 150, 585-598 (2017).

12. Ho, N.M.: Experimental and Theoretical Studies on Three-side Restrained Reinforced Concrete Walls. PhD Thesis, Griffith University, Australia (2018).

13. Baker, C., Chen, B., Drysdale, R.: Failure Line Method Applied to Walls with Openings. In: 10th Canadian Masonry Symposium, Alberta, Canada (2005).

14. AS3600: Concrete Structures. Sydney, NSW, Australia: Standards Australia International (2018). 